\title{
A study on depression, anxiety and illness symptoms according to severity classification of liver cirrhosis patients in South Korea.
}

\author{
Jung-Hyun Seo' ${ }^{1}$, Hyang-Sook Ryu ${ }^{1}$, Youn-Young Lee ${ }^{1}$, Myeong-Jong Kim², Young-Soon Choi ${ }^{\text {* }}$ \\ ${ }^{1}$ Department of Nursing, Gangneung Asan Hospital, Sacheon-Myeon, Gangneung-si, Republic of Korea \\ ${ }^{2}$ Department of Management Information System, Catholic Kwandong University, Gangneung-si, Republic of Korea \\ ${ }^{3}$ Department of Nursing, College of Health Science, Kangwon National University, Samcheok-si, Republic of Korea
}

\begin{abstract}
This study is a descriptive study to investigate the degree of anxiety and depression and the frequency of major symptoms in liver cirrhosis patients and to confirm the correlation between them. In order to collect the data, a joint researcher visits the outpatient department of the gastric medicine and the ward from December 28, 2015 to September 30, 2016, the questionnaire was delivered and collected directly to the subjects. In patients with liver cirrhosis, the mean depression was 15.11, the anxiety was 11.46, and the symptom experience was $\mathbf{2 6 . 1 3}$, which was not significant. In the severity classification according to the Child-Push Score, Child A was significantly lower in depression than Children B and C. In the symptomatic experience, Child A was significantly lower than Children B and C, on the other hand, there was no significant difference between Children A-C in anxiety. The experience of disease symptom showed no significant correlation with anxiety and depression, anxiety and depression were positively correlated. Therefore, for effective symptom management for patients with liver cirrhosis, it is necessary to identify the severity of the disease and to provide nursing intervention accordingly. In addition, nursing intervention for patients with liver cirrhosis requires physical aspects as well as psychological nursing intervention.
\end{abstract}

Keywords: Depression, Anxiety, Illness symptoms, Severity classification, Liver cirrhosis.

Accepted on August 30, 2018

\section{Introduction}

Liver cirrhosis is known to be attributed to diseases that are histopathologically accompanied by hepatic tissue parenchyma atrophy, diffuse fibrosis, the formation of irregular regenerative nodules, and the necrosis and regeneration of the liver tissue and the clinical symptoms of it vary with the complication [1].

Liver cirrhosis is one of chronic diseases. In the Republic of Korea, the prevalence of liver cirrhosis is especially high, and that is one of the major causes of death [2].

For liver cirrhosis patients, life becomes meaningless due to symptom-related physical problems, psychological problems such as depression and anxiety, frequent rehospitalization resulting from complications and worsening symptoms, and subsequent financial difficulty [3]. An earlier study found that approximately $45 \%$ to $55 \%$ of liver cirrhosis patients experience emotional problems such as depression and anxiety [4]. According to the study, depression especially has negative impacts on the coping level, functional status and quality of life of these patients. Another study found that patients who are depressed lag behind patients who aren't in terms of physical, social and functional role performance, that depression exerts adverse influences on current health state, that the depressed liver cirrhosis patients complain of more serious physical pain, and that they fell behind liver cirrhosis patients who aren't depressed in terms of not only the quality of life but adaptive coping and functional status [5].

Keeping track of the psychological needs of liver cirrhosis patients seems to be more important than anything else to have the right understanding of their psychological problems to provide them with quality nursing services, and it's also required to approach them in a way to satisfy their needs. The purpose of this study was to examine the depression, anxiety and illness symptoms of liver cirrhosis patients by the severity of the disease and influential illness symptoms and factors for depression and anxiety in an effort to determine the focus of nursing intervention and the right time for that. It's basically meant to provide some information on how to offer intervention to improve the quality of life of liver cirrhosis patients. 


\section{Research Method}

\section{Research design}

This study is a descriptive study to investigate the degree of anxiety and depression, the frequency of major symptoms of liver cirrhosis, and the correlation between them.

\section{Research subjects}

The subjects of this study were hospitalized or admitted for treatment of liver cirrhosis during the period from December 28, 2015 to September 30, 2016 at the general hospital in G city, Gangwon province.

The exclusion criteria are as follows. First, a person diagnosed with malignancy within 5 years. Second, patients with severe medical, psychiatric, or neurological disorders such as severe renal impairment, severe pulmonary disease, severe cardiovascular disease, and severe metabolic disease. Third, the person who cannot understand or provide the consent form.

\section{Research tools}

1) Depression: The Korean version of the BDI-II (Beck Depression Inventory-II) used for the measurement of depression was a self-report standardization test [6], developed by Aaron [7]. As the fourth edition (Diagnostic and Statistical Manual of Mental Disorders, fourth edition, forthcoming DSM-IV) of the Diagnostic and Statistical Manual of Mental Disorders was published, it was revised to the second edition in accordance with the criteria for diagnosis of depressive symptoms [8]. BDI-II is a 4-point Likert scale with 0 3 points and scores ranging from $0 \sim 63$ points using the total score of 21 items. In this study, the reliability of the instrument was Cronbach's alpha $=0.903$.

2) Anxiety: Korean version of the BAI (Beck anxiety inventory): The Korean version of the BAI (Beck Anxiety Inventory), which measures the anxiety, is a self-report questionnaire consisting of 21 items, covering the cognitive domain, emotional domain, and physical domain, and is rated on a 0-3 point Likert scale. The reliability of the measurement tools in this study was Cronbach's alpha $=0.919$.

3) Symptom experience: In a study by Kim, in the three dimensions of symptom frequency, intensity, and pain in patients with liver cirrhosis, the score difference between the three dimensions was not statistically significant, the frequency score is the highest [9], in this study, 17 items of symptom domain were used for the Korean version of LDQOL 1.0 (Liver Disease Quality of Life 1.0) developed for the patients with chronic liver disease. The reliability of the instrument in this study was Cronbach's alpha $=0.925$.

4) Severity classification of liver cirrhosis (Child-Pugh score): The Child-Pugh Score is based on five variables: serum bilirubin level, albumin level, prothrombin time, hepatic encephalopathy, as a measure of the prognosis of hepatocellular carcinoma and the course of disease [10], it is the most widely used measure of cirrhosis severity and prognosis index. Based on the 5 variables, the Child-Pugh score is 5-6 points for $\mathrm{A}, 7-9$ points for $\mathrm{B}$, and 10 points or more for $\mathrm{C}$.

\section{Ethical considerations}

This study was approved by the Institutional Bioethics Review Board (approval number: 2015-025) of the study hospital.

In addition, those who agree with the screening criteria for which they agree with the department heads are those who understand the research purpose and agree in writing. The collected data are not disclosed or used except for the purpose of the research, and the subject can refuse or stop participating in the study at any time during the course of the research.

\section{Data collection and statistical analysis}

In order to collect the data, a joint researcher visits the outpatient department of the gastric medicine and the ward from December 28, 2015 to September 30, 2016, the questionnaire was delivered and collected directly to the subjects. The response time for the questionnaire was 20 30 min per person, the researcher explained the patient's question about the question.

The sample size was calculated using the $\mathrm{G} *$ Power 3.1 analysis software. The minimum sample size required for crossover analysis was set at significance level $(\alpha) 0.05$, the effect size was 0.3 , and the power $(1-\beta)$ was $80 \%$, the minimum sample size was calculated as 88 , a total of 110 subjects were selected for the study, considering the drop rate of $20 \%$, however 85 questionnaires were collected for 85 questions $(100 \%)$, and 80 questions were used for data analysis, excluding 5 incomplete questionnaires. The collected data were analysed using SPSS-PC 23.0 for Window (SPSS Inc., Chicago, USA).

1) The general characteristics and disease-related characteristics of liver cirrhosis patients were analysed by real numbers and percentages.

2) Crossover analysis and Fisher's exact test were performed to determine the general characteristics and disease-related characteristics of liver cirrhosis patients.

3) The anxiety, depression, and disease symptom experience of liver cirrhosis patients were assessed by mean and standard deviation, and differences between groups were determined by nonparametric Mann-Whitney U test.

4) The differences in the anxiety, depression, and symptom experience according to the general characteristics of liver cirrhosis patients were evaluated by nonparametric MannWhitney U test and Kruskal-Wallis test.

5) Pearson's correlation between anxiety, depression, and symptom experience in patients with liver cirrhosis was analysed. 
A study on depression, anxiety and illness symptoms according to severity classification of liver cirrhosis patients in South Korea

\section{Results}

\section{Severity classification according to general} characteristics of liver cirrhosis patients (Children AC)

The differences in the general characteristics according to the Child-Pugh classification of the disease severity classification of liver cirrhosis patients, in the presence of smoking, the percentage of smokers was significantly higher in child $\mathrm{B}$ and
$\mathrm{C}$ than in child A $\left(\chi^{2}=5.941, \mathrm{p}=0.022\right)$, there were no significant differences in other general characteristics. In terms of disease-related characteristics, children $\mathrm{B}$ and $\mathrm{C}$ were more complicated than child $\mathrm{A}$ in the presence of complications $\left(\chi^{2}=52.595, p=0.019\right)$, the duration of the disease is higher in child $\mathrm{A}$ than in child $\mathrm{B}, \mathrm{C}$ for more than one year, in less than 1 year, children $\mathrm{B}$ and $\mathrm{C}$ were significantly higher than child $\mathrm{A}$ $\left(\chi^{2}=7.388, p=0.024\right)$, but no significant difference was found in other characteristics (Table 1).

Table 1. Severity classification according to general characteristics of liver cirrhosis patients (Children A-C) ( $n=80)$.

\begin{tabular}{|c|c|c|c|c|c|}
\hline \multirow[t]{2}{*}{ Variable } & \multirow[t]{2}{*}{ Division } & & \multirow{2}{*}{$\begin{array}{l}\text { Child A } \\
\text { n (\%) }\end{array}$} & \multirow{2}{*}{$\begin{array}{l}\text { Children B and C } \\
\mathrm{n}(\%)\end{array}$} & \multirow[t]{2}{*}{$x^{2}(p)$} \\
\hline & & & & & \\
\hline \multirow[t]{17}{*}{ General characteristics } & Gender & Male & $32(76.2 \%)$ & $29(76.3 \%)$ & $0.000(1.000)$ \\
\hline & & Female & $10(23.8 \%)$ & $9(23.7 \%)$ & \\
\hline & Marital status & Single & $4(9.5 \%)$ & $6(15.8 \%)$ & $0.716(0.505)$ \\
\hline & & Married & $38(90.5 \%)$ & $32(84.2 \%)$ & \\
\hline & Monthly income & Less than 1 million won & $13(31.0 \%)$ & $10(26.3 \%)$ & $0.592(0.847)$ \\
\hline & & 101-199 million won & $11(26.2 \%)$ & $12(31.6 \%)$ & \\
\hline & & 201-299 million won & $8(19.0 \%)$ & $6(15.8 \%)$ & \\
\hline & & More than 3 million won & $10(23.8 \%)$ & $10(26.3 \%)$ & \\
\hline & Age & Under 50 years & $10(23.8 \%)$ & $10(26.3 \%)$ & $0.174(0.960)$ \\
\hline & & 50 to 60 years & $17(40.5 \%)$ & $14(36.8 \%)$ & \\
\hline & & More than 61 years & $15(35.7 \%)$ & $14(36.8 \%)$ & \\
\hline & Job & Yes & $21(50.0 \%)$ & $18(47.4 \%)$ & $0.055(0.827)$ \\
\hline & & No & $21(50.0 \%)$ & $20(52.6 \%)$ & \\
\hline & Drinking & Yes & $19(45.2 \%)$ & $22(57.9 \%)$ & $1.279(0.273)$ \\
\hline & & No & $23(54.8 \%)$ & $16(42.1 \%)$ & \\
\hline & Smoking & Yes & $11(26.2 \%)$ & $20(52.6 \%)$ & $5.941^{*}(0.022)$ \\
\hline & & No & $31(73.8 \%)$ & $18(47.4 \%)$ & \\
\hline \multirow[t]{11}{*}{ Disease-related characteristics } & Accompanying disease & 0 & $23(54.8 \%)$ & $23(60.5 \%)$ & $0.348(0.943)$ \\
\hline & & 1 & $15(35.7 \%)$ & $12(31.6 \%)$ & \\
\hline & & 2 & $4(9.5 \%)$ & $3(7.9 \%)$ & \\
\hline & Number of hospitalizations & None & $6(14.3 \%)$ & $0(0.0 \%)$ & $12.106^{*}(0.014)$ \\
\hline & & 1 & $14(33.3 \%)$ & $6(15.8 \%)$ & \\
\hline & & 2 & $8(19.0 \%)$ & $15(39.5 \%)$ & \\
\hline & & 3 & $7(16.7 \%)$ & $6(15.8 \%)$ & \\
\hline & & More than 4 & $7(16.7 \%)$ & $11(28.9 \%)$ & \\
\hline & Causes of liver cirrhosis & HBV & $13(31.0 \%)$ & $9(23.7 \%)$ & $2.360(0.528)$ \\
\hline & & $\mathrm{HCV}$ & $3(7.1 \%)$ & $2(5.3 \%)$ & \\
\hline & & Alcohol & $21(50.0 \%)$ & $25(65.8 \%)$ & \\
\hline
\end{tabular}




\begin{tabular}{|c|c|c|c|c|}
\hline & Etc. & $5(11.9 \%)$ & $2(5.3 \%)$ & \\
\hline \multirow[t]{3}{*}{ Duration of disease } & Less than 1 year & $7(16.7 \%)$ & $16(42.1 \%)$ & $7.388^{*}(0.024)$ \\
\hline & $1-5$ years & 18 (42.9\%) & $8(21.1 \%)$ & \\
\hline & More than 6 years & $17(40.5 \%)$ & $14(36.8 \%)$ & \\
\hline \multirow[t]{2}{*}{ Complication } & Yes & $21(50.0 \%)$ & $28(75.7 \%)$ & $5.506^{*}(0.019)$ \\
\hline & No & $21(50.0 \%)$ & 9 (24.3\%) & \\
\hline
\end{tabular}

${ }^{*} p<0.05,{ }^{* *} p<0.01,{ }^{* * *} p<0.001$

\section{Anxiety, depression and disease symptoms according to general characteristics of liver cirrhosis patients}

The differences in the anxiety, depression, and disease symptom experience according to the general characteristics of the subjects of liver cirrhosis without regard to the subjects A$\mathrm{C}$, in the case of marital status, statistically significant differences were found in anxiety $(\mathrm{U}=152.500, \mathrm{p}=0.004)$ and depression $(\mathrm{U}=121.000, \mathrm{p}=0.001)$, anxiety and depression were higher in unmarried than in married. There was a statistically significant difference in drinking anxiety ( $\mathrm{U}=510.000$, $\mathrm{p}=0.005)$, and drinkers were more anxious than non-drinkers.

There was a statistically significant difference in smoking anxiety $(\mathrm{U}=474.500, \mathrm{p}=0.005)$ and depression $(\mathrm{U}=417.500$, $\mathrm{p}=0.001)$. Smokers were higher in both anxiety and depression than non-smokers (Table 2).

Table 2. Anxiety, depression and experience illness symptoms according to general characteristics of liver cirrhosis patient $(n=80)$.

\begin{tabular}{|c|c|c|c|c|c|c|c|}
\hline \multirow[t]{2}{*}{ Variable } & & \multicolumn{2}{|l|}{ Anxiety } & \multicolumn{2}{|l|}{ Depression } & \multicolumn{2}{|c|}{ Experience illness symptoms } \\
\hline & & $N(M \pm S D)$ & $U(p)$ & $N(M \pm S D)$ & $U(p)$ & $N(M \pm S D)$ & $U(p)$ \\
\hline \multirow[t]{2}{*}{ Marital status } & Single & $70(10.00 \pm 7.14)$ & $152.500^{\dagger}(0.004)$ & $70(13.81 \pm 8.85)$ & $121.00 \ddagger(0.001)$ & $70(28.30 \pm 14.06)$ & $302.5(0.489)$ \\
\hline & Married & $10(21.70 \pm 13.78)$ & & $10(24.20 \pm 8.88)$ & & $10(28.30 \pm 14.06)$ & \\
\hline \multirow[t]{2}{*}{ Drinking } & Yes & $41(14.24 \pm 10.10)$ & $510.000^{\dagger}(0.005)$ & $41(17.02 \pm 11.04)$ & $650.5(0.151)$ & $41(27.54 \pm 16.44)$ & $702.5(0.35)$ \\
\hline & No & $39(13.10 \pm 7.01)$ & & $39(13.10 \pm 7.01)$ & & $39(24.64 \pm 17.63)$ & \\
\hline \multirow[t]{2}{*}{ Smoking } & Yes & $31(14.29 \pm 8.29)$ & $474.500^{\dagger}(0.005)$ & $31(20.13 \pm 11.09)$ & $417.500 \ddagger(0.001)$ & $31(27.00 \pm 14.29)$ & $675(0.404)$ \\
\hline & No & $49(9.67 \pm 9.09)$ & & $49(11.94 \pm 6.60)$ & & $49(25.57 \pm 18.61)$ & \\
\hline
\end{tabular}

${ }^{*} p<0.05,{ }^{\dagger} p<0.01,{ }^{\ddagger} p<0.001$.

\section{Differences in experience of anxiety, depression and illness symptoms according to disease classification in liver cirrhosis}

Anxiety, depression, and illness symptoms according to children A-C classification of the subjects, depression was significantly lower in child $\mathrm{A}$ than in children $\mathrm{B}$ and $\mathrm{C}$ $(\mathrm{U}=578.500, \mathrm{p}=0.034)$, in the experience of illness symptoms, child A was significantly lower than children B and C $(\mathrm{U}=539.500, \mathrm{p}=0.013)$. On the other hand, there was no significant difference between children A-C in anxiety (Table $3)$.

Table 3. Differences in experience of anxiety, depression and illness symptoms according to disease classification in liver cirrhosis $(n=80)$.

\begin{tabular}{lllll}
\hline Variable & Child A & Children B and C & U & p \\
\cline { 2 - 3 } & $\mathbf{n}(\mathbf{M} \pm \mathbf{S D})$ & $\mathbf{n}(\mathbf{M} \pm \mathbf{S D})$ & & \\
\hline Anxiety & $42(11.31 \pm 10.12)$ & $38(11.63 \pm 7.76)$ & 721.5 & 0.46 \\
\hline
\end{tabular}

\begin{tabular}{lcccc} 
Depression & $42(12.90 \pm 8.03)$ & $38(17.55 \pm 10.37)$ & $578.500^{*}$ & 0.034 \\
\hline $\begin{array}{l}\text { Illness } \\
\text { symptoms }\end{array}$ & $42(22.81 \pm 18.52)$ & $38(29.79 \pm 14.48)$ & $539.500^{*}$ & 0.013 \\
\hline${ }^{*}<<0.05,{ }^{\dagger} p<0.01,{ }^{\ddagger} p<0.001$. & & & \\
\hline
\end{tabular}

\section{The relationship between anxiety, depression, and illness symptoms in patients with liver cirrhosis}

Anxiety, depression, and experience of disease symptoms were analysed by correlation analysis, anxiety in patients with liver cirrhosis was positively correlated with depression $(\mathrm{r}=0.533$, $\mathrm{p}=0.000$ ). In other words, the more the anxiety was, the more the depression was increased. The experience of illness symptoms in patients with liver cirrhosis was not statistically significant with depression $(\mathrm{r}=0.193, \mathrm{p}=0.087)$ and anxiety $(\mathrm{r}=0.074, \mathrm{p}=0.514)$ (Table 4).

Table 4. The relationship between anxiety, depression, and illness symptoms in patients with liver cirrhosis $(n=80)$. 

South Korea

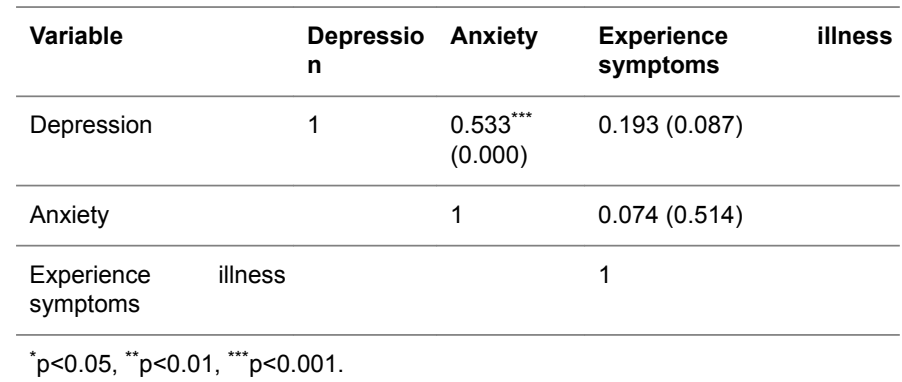

management, it seems necessary to have a perfect understanding of differences in anxiety, depression and illness symptoms according to liver cirrhosis severity to provide more careful and successful nursing intervention.

\section{Conclusion}

This study is a descriptive study to investigate the degree of anxiety and depression and the frequency of major symptoms in liver cirrhosis patients and to confirm the correlation between them.

\section{Discussion}

In this study, the depression and anxiety of the liver cirrhosis patients and the frequency of their illness symptoms were investigated in consideration of the severity of the disease, and what symptoms and factors affected depression and anxiety was analysed to find out what should be the focus of nursing intervention and when to offer it in order to provide information on what intervention should be prepared to improve their quality of life.

As for the severity of liver cirrhosis of the subjects, the childpugh class A patients accounted for $52.5 \%$, and the rate of the child-pugh class B patients stood at $33.8 \%$. The former was larger in number because the data were gathered mostly from the OPDs. Usually, many inpatients are child-pugh class $\mathrm{C}$ patients who suffer from various symptoms due to complications or have difficulty with getting around. While this study was implemented, the patients who met the hospitalization criteria were relatively small in number.

The unmarried live cirrhosis patients felt more anxiety than the married ones, and this finding is similar to the finding of Lee's study. Sung's study of patients with liver diseases established that smooth communication among the family members is a protective factor to relieve depression [11]. Thus, getting married seems to be one of crucial factors to decrease the anxiety and depression of liver cirrhosis patients.

The live cirrhosis patients got a mean of 15.11 in depression, which is higher than the mean depression scores in studies of chronic liver diseases that were 8.28 [12] and 10.7 [13]. Since liver cirrhosis is difficult to treat completely, this characteristic seems to have been affected by the financial burden of longterm treatment that entailed sustained management, regular hospital visits and diet therapy [12]. This seems to be similar to the characteristics of other chronic diseases.

The symptom items that the patients experienced a lot were frequent urine, waning vitality and widespread pain. As a result of analyzing their symptoms by liver cirrhosis severity, limb edema and ascites were the items that were dominant in the groups of the child-pugh classes $\mathrm{B}$ and $\mathrm{C}$ patients. So it's required to make an accurate analysis of physical symptoms by severity when nursing assessment is fulfilled.

The findings of the study suggest that chronic liver cirrhosis patients are especially in need of sustained disease surveillance to minimize barriers to daily life and maintain current functional status. To ensure the effectiveness of symptom

In patients with liver cirrhosis, the mean depression was 15.11 , the anxiety was 11.46 , and the symptom experience was 26.13 , which was not significant. In the severity classification according to the Child-Push Score, child A was significantly lower in depression than children B and C. In the symptomatic experience, child A was significantly lower than children $\mathrm{B}$ and $\mathrm{C}$, on the other hand, there was no significant difference between children A-C in anxiety. The experience of disease symptom showed no significant correlation with anxiety and depression, anxiety and depression were positively correlated.

Therefore, for effective symptom management for patients with liver cirrhosis, it is necessary to identify the severity of the disease and to provide nursing intervention accordingly. In addition, nursing intervention for patients with liver cirrhosis requires physical aspects as well as psychological nursing intervention.

\section{Conflict of Interest}

The authors report no conflicts of interest related to this study. The author does not have any financial interest in the companies whose materials are included in the article.

\section{References}

1. Han YS. A Study on trend analysis of the causes and complications of liver cirrhosis. J Hepatology 2000; 6: 328-339.

2. Korean Association for the Study of the Liver. Clinical practice guideline for liver cirrhosis 2011.

3. Lee HS. A study of psychosocial needs of cirrhosis patients. Unpublished Master's Thesis. Sangji University, Gangwon-do 2009.

4. Rocca P, Couzza E, Rasetti R, Rocca G, Zanalda E, Bogegetto F. Predictors of psychiatric in liver transplantation candidates: logistic regression models. Liver Transpl 2003; 9: 721-726.

5. Singh NGT, Wagener MM, Marino IR. Depression in patients with cirrhosis. Impact on outcome. Dig Dis Sci 1997; 42: 1421-1427.

6. Hahn DW, Pyo SY. Predictions of subjective well-being, health perception and physical illness from emotional experiences in everyday life. Korean J Health Psychol 2002; 7: 403-427.

7. Beck AT. Depression: clinical, experimental and theoretical aspects. NY Harper Low 1967. 
8. Beck AT, Steer RA, Brown GK. Beck depression inventories (2nd Manual). San antonio: Psychol Corp 1996; 1-82.

9. Kim SH. Factors influencing symptom experience in patients with liver cirrhosis. J Korean Acad Soc Adult Nurs 2005; 17: 248-258.

10. Pugh RNH, Murray-lyon IM, Dawson JL, Pietroni MC, Williams R. Trans-section of the esophagus for bleeding esophageal varices. Br J Surg 1973; 60: 646-649.

11. Sung, HM, Kim JB, Park, YN, Bai DS, Lee SH, Ahn HN. A study on the reliability and the validity of korean version of the Beck Depression Inventory-II (BDI-II). J Korean Soc Biol Ther Psychiatry 2008; 14: 201-212.

12. Park YH, Lee EN. A study of fatigue and daily living activity in patients with chronic liver disease. Korean $\mathrm{J}$ Rehabil Nurs 2005; 8: 110-118.
13. Kim JS, Hong HS. Construction of model for healthrelated quality of life of liver cirrhosis patients. J Korean Biol Nurs Sci 2014; 16: 292-299.

\section{*Correspondence to}

Young-Soon Choi

Department of Nursing

College of Health Science

Kangwon National University

Republic of Korea 